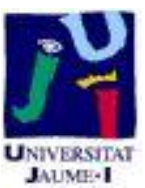

Título artículo / Títol article: Interaction of the chromium-iron black pigment with porcelanised stoneware

Autores / Autors

Mestre Beltrán, Sergio ; Gómez, P. ; Gazulla Barreda, María Fernanda ; Gozalbo Nebot, Ana

Revista:

Ceramics International, 2013, vol. 39, no 7

Versión / Versió:

Postprint del autor

Cita bibliográfica / Cita

MESTRE, S., et al. Interaction of the chromium-iron bibliogràfica (ISO 690): black pigment with porcelanised stoneware. Ceramics International, 2013, vol. 39, no 7, p. 7453-7459

url Repositori UJI:

http://hdl.handle.net/10234/92077 


\section{AUTHOR QUERY FORM}

\begin{tabular}{|c|c|c|}
\hline ELSEVIER & $\begin{array}{l}\text { Journal: CERI } \\
\text { Article Number: } 6499\end{array}$ & $\begin{array}{l}\text { Please e-mail or fax your responses and any corrections to: } \\
\text { E-mail: corrections.eseo@elsevier.macipd.com } \\
\text { Fax: }+441392285878\end{array}$ \\
\hline
\end{tabular}

Dear Author,

Please check your proof carefully and mark all corrections at the appropriate place in the proof (e.g., by using on-screen annotation in the PDF file) or compile them in a separate list. Note: if you opt to annotate the file with software other than Adobe Reader then please also highlight the appropriate place in the PDF file. To ensure fast publication of your paper please return your corrections within 48 hours.

For correction or revision of any artwork, please consult http://www.elsevier.com/artworkinstructions.

Any queries or remarks that have arisen during the processing of your manuscript are listed below and highlighted by flags in the proof. Click on the $\underline{Q}$ link to go to the location in the proof.

\begin{tabular}{|c|c|}
\hline $\begin{array}{l}\text { Location in } \\
\text { article }\end{array}$ & $\begin{array}{l}\text { Query / Remark: click on the Q link to go } \\
\text { Please insert your reply or correction at the corresponding line in the proof }\end{array}$ \\
\hline $\mathrm{Q} 1$ & $\begin{array}{l}\text { Please confirm that given names and surnames have been identified correctly and are presented in } \\
\text { the desired order. }\end{array}$ \\
\hline $\mathrm{Q} 2$ & $\begin{array}{l}\text { Please check the edit(s) made in the sentence "The B..... were compared", and correct if } \\
\text { necessary. }\end{array}$ \\
\hline Q3 & $\begin{array}{l}\text { Please check the edit(s) made in the sentence "The cycle.......air injection", and correct if } \\
\text { necessary. }\end{array}$ \\
\hline Q4 & $\begin{array}{l}\text { Please check the edit(s) made in the sentence "The arising........ICDD cards", and correct if } \\
\text { necessary. }\end{array}$ \\
\hline
\end{tabular}

Thank you for your assistance. 


\title{
Interaction of the chromium-iron black pigment with porcelanised stoneware
}

\author{
S. Mestre*, P. Gómez, M.F. Gazulla, A. Gozalbo \\ Instituto de Tecnología Cerámica, Asociación de Investigación de las Industrias Cerámicas, Universitat Jaume I, Castellón, Spain
}

Received 16 November 2012; received in revised form 15 February 2013; accepted 26 February 2013

\begin{abstract}
A study has been undertaken on the interaction between the $(\mathrm{Fe}, \mathrm{Cr})_{2} \mathrm{O}_{3}$ black pigment and an industrial porcelanised stoneware composition at its firing temperature. The results indicate that the glassy phase that forms during firing preferentially extracts $\mathrm{Fe}_{2} \mathrm{O}_{3}$ from the pigment and probably contributes some $\mathrm{Al}_{2} \mathrm{O}_{3}$ to it, enriching the pigment composition in $\mathrm{Cr}_{2} \mathrm{O}_{3}$, without changing pigment crystal structure. The pigment alteration process mainly affects porcelanised stoneware microstructure and, to a lesser extent, color. (c) 2013 Published by Elsevier Ltd and Techna Group S.r.l.
\end{abstract}

Keywords: C. Color; Ceramic pigments; Porcelanised stoneware; Reaction

\section{Introduction}

The $(\mathrm{Fe}, \mathrm{Cr})_{2} \mathrm{O}_{3}$ pigment, known as chromium-iron black, has long been used in the ceramic industry [1,2], despite its tendency to produce brown hues [3]. However, the rise in price of cobalt-based black pigments has increased interest in optimizing the characteristics of this pigment.

The $(\mathrm{Fe}, \mathrm{Cr})_{2} \mathrm{O}_{3}$ pigment is synthesized by heat treatment at temperatures around $1000{ }^{\circ} \mathrm{C}$ from a mixture of $\mathrm{Cr}_{2} \mathrm{O}_{3}$ and $\mathrm{Fe}_{2} \mathrm{O}_{3}$, whose proportions vary depending on the characteristics of the pigment to be obtained, to which small quantities of certain salts may be added as mineralisers. Structurally, the pigment is a substitutional solid solution with a corundum-type crystalline network. The $\mathrm{Fe}^{3+}$ and $\mathrm{Cr}^{3+}$ cations occupy two-thirds of the octahedral vacancies in the compact hexagonal network formed by the oxygen anions, and are randomly distributed according to their proportion in the mixture. A solid solution forms in the entire range of compositions at temperatures below $1380^{\circ} \mathrm{C}$,

\footnotetext{
*Correspondence to: Instituto de Tecnología Cerámica, Asociación de Investigación de las Industrias Cerámicas, Universitat Jaume I, Campus Universitario Riu Sec, s/n, 12006 Castellón, Spain. Tel.: + 34964 342424; fax: +34964342425 .

E-mail addresses: smestre@itc.uji.es, marije.jose@itc.uji.es (S. Mestre).
}

while a different phase appears at higher temperatures, with a spinel-type structure [4]. The pigment synthesis reaction mechanism has been described elsewhere [5], and a kinetic equation has been proposed which contains the effect of synthesis temperature, reactant quantities and particle size distribution [6,7].

Less attention has generally been devoted to the interaction, during firing, of pigments with different ceramic products into which they have been incorporated. A few available studies focus on the interaction between pigments and different types of glazes (chrome-tin pink sphene [8-10], brown $\mathrm{Cr}-\mathrm{Fe}-\mathrm{Zn}-\mathrm{Al}$ spinel [11], and also the chromium-iron black [12]). More recently, inkjet technology has promoted the study of interactions between glazes and nanosized pigments [13]. However, pigment interactions with other types of ceramic products have not been addressed. The $(\mathrm{Fe}, \mathrm{Cr})_{2} \mathrm{O}_{3}$ pigment is extensively used in coloring porcelanised stoneware, a ceramic floor tile made essentially from quartz, feldspars and white clays, which is fired at relatively high temperatures $\left(1180-1200{ }^{\circ} \mathrm{C}\right)$. Fired porcelanised stoneware has practically zero apparent porosity and low closed porosity. From a mineralogical point of view porcelanised stoneware consists mainly of glassy phase that contains dispersed particles of quartz and mullite (mullite develops during heating as a product of the thermal decomposition of kaolinitic clays, and during 
1 the residence at peak temperature as a result of devitrification from the glassy phase that forms during firing) [14].

As porcelanised stoneware production has increased notably in the last decade, and much porcelanised stoneware is colored to improve tile esthetic qualities, the present study has been undertaken to identify the interaction mechanism between the $(\mathrm{Fe}, \mathrm{Cr})_{2} \mathrm{O}_{3}$ black pigment and the porcelanised stoneware, and to determine the effect of this interaction on the microstructure, mineralogical composition and color of the fired tile. This information is necessary to improve the pigment characteristics.

\section{Experimental procedure}

The study has been conducted with an industrial black pigment that had a composition of approximately $\mathrm{Fe}_{1.28}$ $\mathrm{Cr}_{0.72} \mathrm{O}_{3}$, whose only crystalline phase was a solid solution with a corundum-type structure (Fig. 1). The porcelanised stoneware was obtained from a typical spray-dried raw materials composition used in the ceramic floor tile industry in Castellón.

Two different mixtures were prepared. The "A" mixture was a blend of $95 \%$ spray-dried porcelanised stoneware composition and $5 \%$ pigment (percentages by weight). The " $\mathrm{B}$ " mixture was the spray-dried porcelanised stoneware composition, without any pigment addition; these served as

Q2 a reference with which the colored samples were compared. Both mixtures were homogenized by wet milling in a planetary mill (Pulverisette 5, Fritsch GmbH, Germany), using acetone as fluid. The resulting suspensions were dried under infrared lamps and the dry powder was put through a $600 \mu \mathrm{m}$ mesh sieve to remove large agglomerates.

The two dry mixtures were moistened to a water content of $0.055 \mathrm{~kg}$ water $/ \mathrm{kg}$ dry solid. Cylindrical test specimens were then formed by uniaxial dry pressing in an automatic laboratory press (P/Mignon, C.C.R. di Nannetti, Italy) at a maximum pressure of $400 \mathrm{~kg} / \mathrm{cm}^{2}$. The resulting

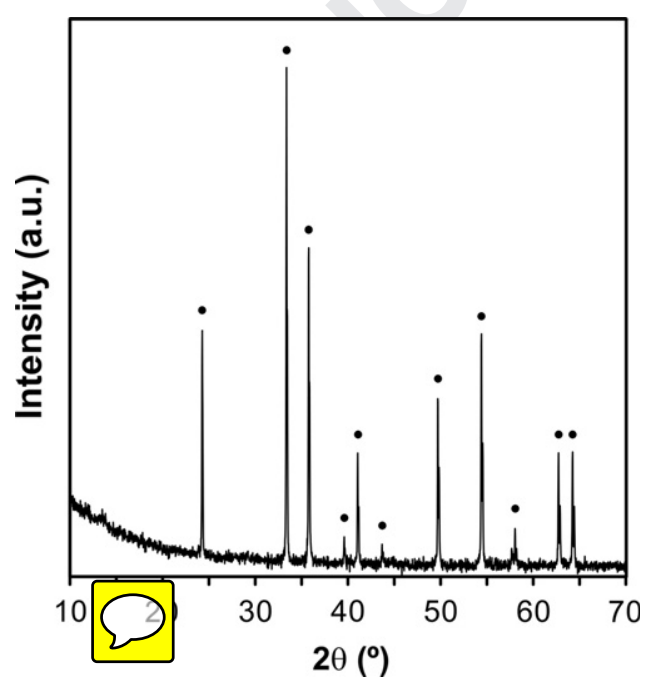

Fig. 1. Diffractogram of the pigment, in which the positions of the reflections corresponding to a $\mathrm{Cr}_{0.8} \mathrm{Fe}_{1.2} \mathrm{O}_{3}$ solid solution are marked. compacts were dried in a laboratory oven at $110^{\circ} \mathrm{C}$ for at least $2 \mathrm{~h}$ before firing.

The test specimens were fired in an electric laboratory furnace (RHF16/8, Carbolite Furnaces Ltd., UK), applying a similar thermal treatment to that used in manufacturing porcelanised stoneware in industrial practice. The cycle consisted of heating at $25^{\circ} \mathrm{C} / \mathrm{min}$ to $1180^{\circ} \mathrm{C} / \mathrm{min}$, which is the appropriate maturing temperature for the Q3 porcelanised stoneware composition used, with different soaking times at this temperature (hereafter $t_{\mathrm{S}}$ ), followed by cooling inside the furnace without air injection. A wide range of soaking times (from 0.1 to $480 \mathrm{~min}$ ) was chosen in order to monitor fully the evolution of the pigmentporcelanised stoneware interaction. Four test specimens of every composition were judiciously arranged inside the furnace chamber in each firing to minimize the effects of possible temperature gradients.

The CIELab chromatic coordinates of the fired test specimens were determined with a diffuse reflectance spectrophotometer (Color-Eye 7000, GretagMacbeth, Switzerland). The measurement was made with a CIE 10-degree standard observer and CIE standard illuminant D65, and included the specular and ultraviolet components. The meaning of the chromatic coordinates is as follows:

- $L^{*}$ is the white $\left(L^{*}=100\right)$, black $\left(L^{*}=0\right)$ axis

$-a^{*}$ is the red $\left(a^{*}>0\right)$, green $\left(a^{*}<0\right)$ axis

$-b^{*}$ is the yellow $\left(b^{*}>0\right)$, blue $\left(b^{*}<0\right)$ axis

The preparation of A and B fired specimens for X-ray diffraction (XRD) differed for each type of samples. The "A" fired test specimens were milled in a ring mill (HSM1000A, Herzog Maschinenfabrik GmbH, Germany) without any further treatment. The "B" fired test specimens were also milled, first, in the ring mill; they were then mixed in the appropriate proportion with the pigment in order to subsequently obtain fired porcelanised stoneware standards in which no interaction had yet occurred with the pigment. Mixing took place in the same planetary mill described above and also with acetone as a fluid; however, in this case, small-volume agate jars were used in view of the small quantity of sample. The resulting suspensions were then dried under infrared lamps and the dry powder was put through a $200 \mu \mathrm{m}$ mesh sieve to remove any large particles.

The crystalline phases were identified from diffractograms obtained with an XRD instrument (D8 Advance, Bruker, Germany) using $\mathrm{Cu} \mathrm{K} \alpha_{1,2}(1.5406 \AA)$ radiation, with a goniometer radius of $250 \mathrm{~mm}$. The data were collected on a diffractometer with Bragg-Brentano geometry $(\Theta / \Theta)$, between $10^{\circ}$ and $70^{\circ}(2 \Theta)$, with a step size of $0.02-0.5 \mathrm{~s}$ per step. The diffractometer optics consisted of a primary system of Soller slits and a fixed aperture of $0.5 \mathrm{~mm}$. A rapid solid-state detector (Vantec, Bruker, Germany) fitted with a system of Soller slits and nickel filter was used. The X-ray tube was operated at $40 \mathrm{kV}$ and 
$140 \mathrm{~mA}$. The results were processed with EVA and TOPAS$\mathrm{P}$ computer programs (Bruker, Germany). The crystalline phases were identified with ICDD cards, as follows: pigment (00-034-0412 (I) Chromium Iron Oxide), quartz (00-046-1045 (*) Quartz, syn), mullite (00-015-0776 (I) Mullite, syn), hematite (00-033-0664 $\left({ }^{*}\right)$ Hematite, syn), and eskolaite (00-038-1479 (*) Eskolaite, syn).

The microstructural changes in the fired test specimens were determined by optical microscopy on fragments of the test specimens embedded in epoxy resin and polished. The changes in pigment particle characteristics were analyzed by scanning electron microscopy (XL30, Philips, The Netherlands) with energy-dispersive microanalysis (DX4, EDAX, USA) on the same polished test specimen fragments used in the microstructural characterization.

\section{Results and discussion}

19

\subsection{Evolution of microstructure}

Figs. 2-4 depict the microstructures of the polished fired test specimens of series "A" and "B", fired at $1180^{\circ} \mathrm{C}$ with different soaking times.

The figures show that the interaction between the porcelanised stoneware and the pigment leads to changes in the microstructure, compared with the non-pigmented specimen microstructure, when the heat treatments are very long. At very short interaction times $\left(t_{\mathrm{S}}=0.1 \mathrm{~min}\right.$, Fig. 2) no differences are observed between the pigmented and nonpigmented specimen microstructures: both microstructures display numerous interconnected pores, corresponding to a reduced degree of sintering. At the usual soaking time for this porcelanised stoneware composition $\left(t_{\mathrm{S}}=18 \mathrm{~min}\right.$, Fig. 3$)$ the product's characteristic microstructure is obtained, which contains closed pores with quite rounded shapes. However, the presence of the pigment is observed leading to slightly more rounded pores, owing to a slightly more fluid glassy phase.

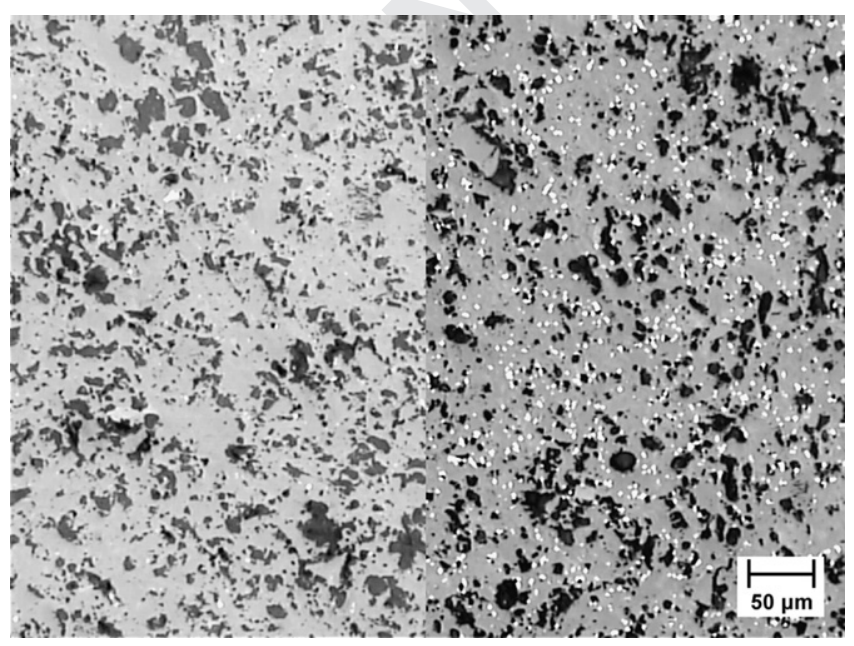

Fig. 2. Microstructures of the fired test specimens at $t_{\mathrm{S}}=0.1 \mathrm{~min}$ (right: A series; and left: B series).
The greatest difference in microstructure develops at the longest soaking times $\left(t_{\mathrm{S}}=480 \mathrm{~min}\right.$, Fig. 4); here, the pigmented specimens display a greater number of pores, which are also larger. Excessively long residence times at peak temperature are known to cause the gas pressure in the pores to increase pore volume until equilibrium is reached between this pressure and the curvature stress of the gas-glassy phase interface, resulting in bloating of the pieces. However, the abnormal development of porosity when the pigment is added implies the existence of an additional source of gases, or the presence of a much less viscous glassy phase. Both mechanisms can act in this case, as discussed in the following section.

\subsection{Evolution of the crystalline phases}

The XRD analysis results indicate that the quantity of quartz decreases as $t_{\mathrm{S}}$ increases, following a logarithmic trend, as evidenced by Fig. 5 in which the reflection intensity

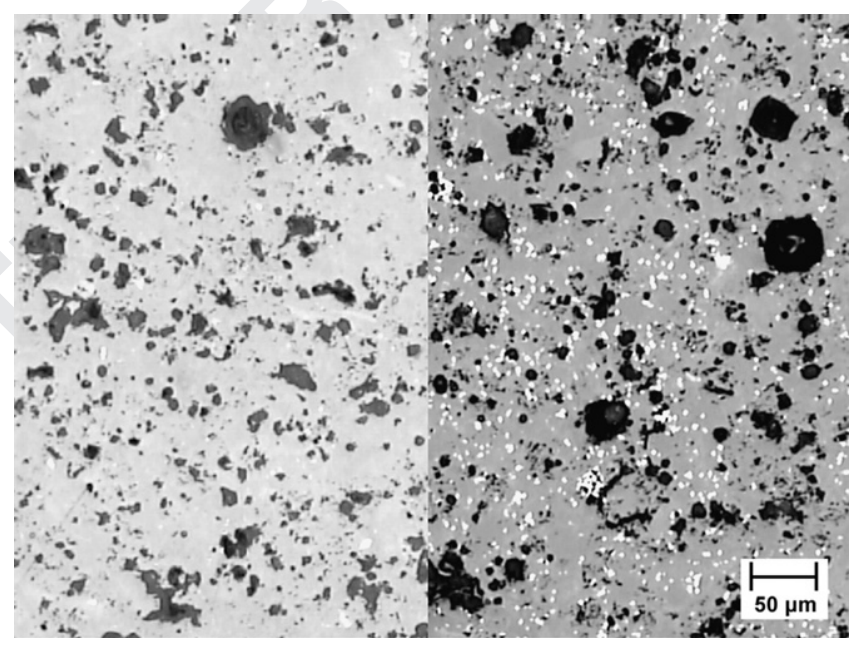

Fig. 3. Microstructures of the fired test specimens at $t_{\mathrm{S}}=18 \mathrm{~min}$ (right: A series; and left: B series).

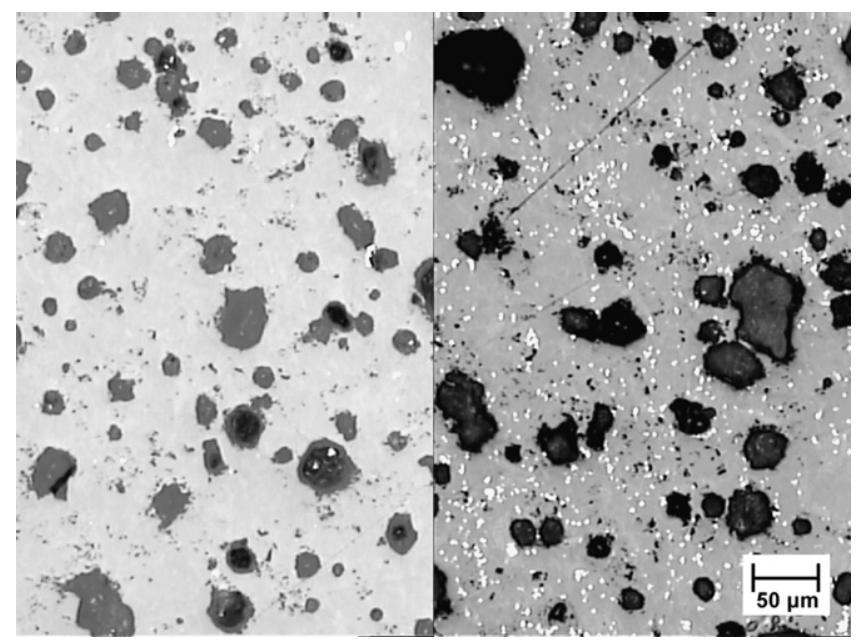

Fig. 4. Microstructures of the fired test specimens at $t_{\mathrm{S}}=480 \mathrm{~min}$ (right: A series; and left: B series). 


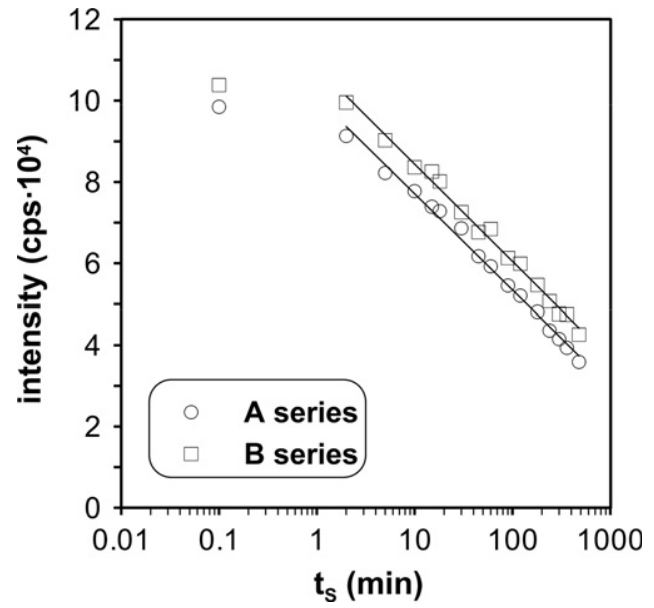

Fig. 5. Evolution of quartz reflection intensity $I_{100}$ with $t_{\mathrm{S}}$.

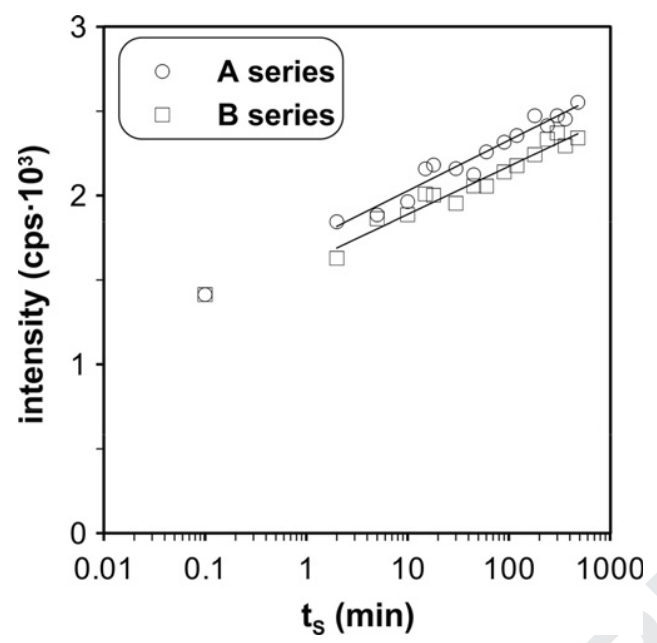

Fig. 6. Evolution of mullite reflection intensity $I_{100}$ with $t_{\mathrm{S}}$.

$I_{100}$ of this phase is plotted against soaking time. The only effect of the presence of the pigment on the evolution of quartz is a reduction in reflection intensity, attributable to the dilution caused by the incorporation of the pigment in conjunction with the increase in the X-ray mass absorption coefficient of the material; however, the pigment does not appear to affect process kinetics, since the two straight lines are practically parallel.

The quantity of mullite increases with $t_{\mathrm{S}}$, as shown by the evolution of the intensity of the $I_{100}$ reflection of this phase (Fig. 6), and approximately follows a logarithmic trend, albeit less clearly than in the case of quartz. As the intensity of the mullite reflections, at the same $t_{\mathrm{S}}$, is always slightly higher in the pigmented specimens (in contrast to what occurs in quartz), this suggests that the presence of the pigment favours genesis of a greater quantity of mullite. However, this effect is only confined to the first stages, since the straight lines display a high degree of parallelism.

Analysis of the reflections corresponding to the pigment indicates that when $t_{\mathrm{S}}$ increases the $I_{100}$ reflection of the solid solution, in addition to diminishing intensity, shifts

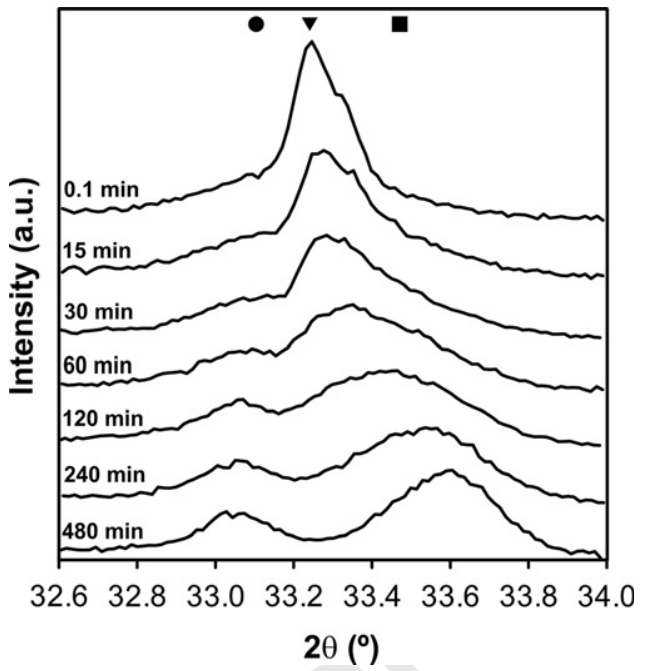

Fig. 7. Detail of the diffractograms corresponding to the main reflection area of the pigment ( pigment, $\square \mathrm{Cr}_{2} \mathrm{O}_{3}, \bullet$ mullite).

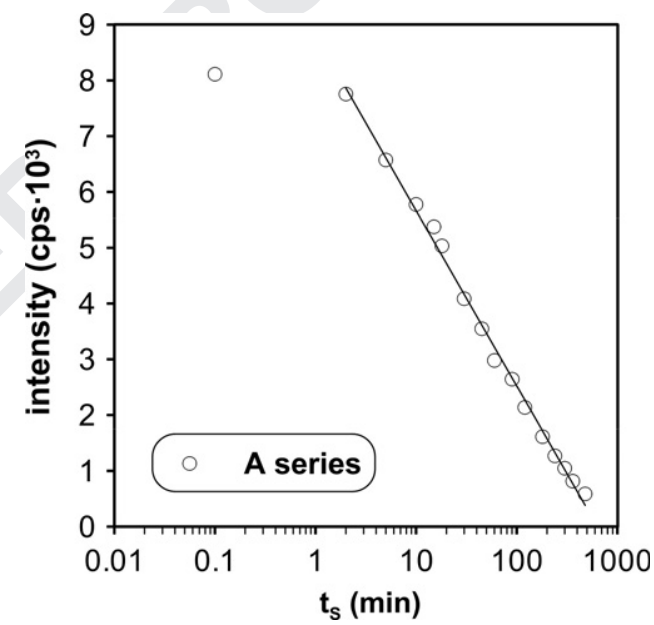

Fig. 8. Evolution of pigment reflection intensity $I_{100}$ with $t_{\mathrm{S}}$.

towards higher $2 \Theta$ angles, even though a clearly defined new reflection does not develop (Fig. 7), as if the pigment structure approached that of pure $\mathrm{Cr}_{2} \mathrm{O}_{3}$. The reflection deconvolution process shows, first, that the intensity of the $I_{100}$ reflection of the solid solution decreases with $t_{\mathrm{S}}$, approximately following a logarithmic trend (Fig. 8) similar to that exhibited by quartz and mullite. Secondly, the intensity corresponding to $\mathrm{Cr}_{2} \mathrm{O}_{3}$ increases with an approximately logarithmic trend up to a maximum at $t_{\mathrm{S}}=120 \mathrm{~min}$ and then decreases again, since the reflection shifts towards angle positions higher than that of $\mathrm{Cr}_{2} \mathrm{O}_{3}$ (Fig. 9). This finding was verified by subjecting pigment particles present in polished cross-sections of series " $A$ " specimens to EDX microanalysis. Fig. 10 compares the atomic $\mathrm{Fe} / \mathrm{Cr}$ and $\mathrm{Al} / \mathrm{Cr}$ ratios of three specimens subjected to very different soaking times. It can be observed that the ratio between the $\mathrm{Fe}$ and $\mathrm{Cr}$ decreases as $t_{\mathrm{S}}$ increases, which confirms that the pigment particles become poorer in $\mathrm{Fe}$, as suggested by the XRD results. 


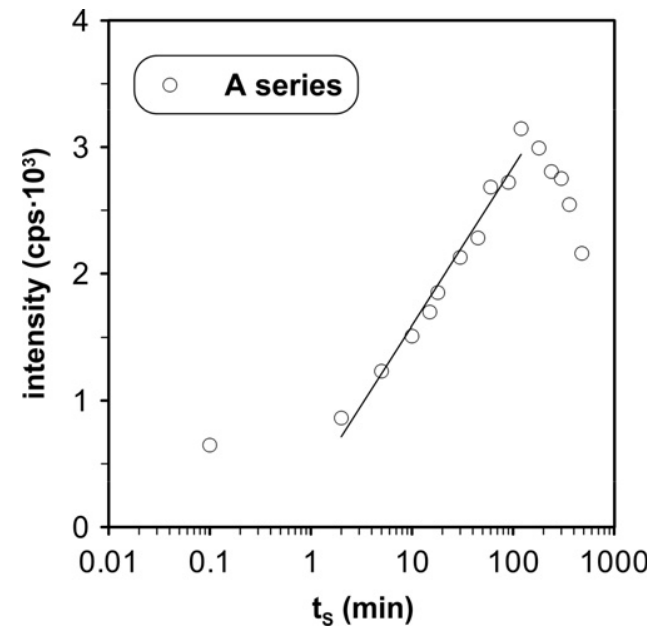

Fig. 9. Evolution of $\mathrm{Cr}_{2} \mathrm{O}_{3}$ reflection intensity $I_{100}$ with $t_{\mathrm{S}}$.

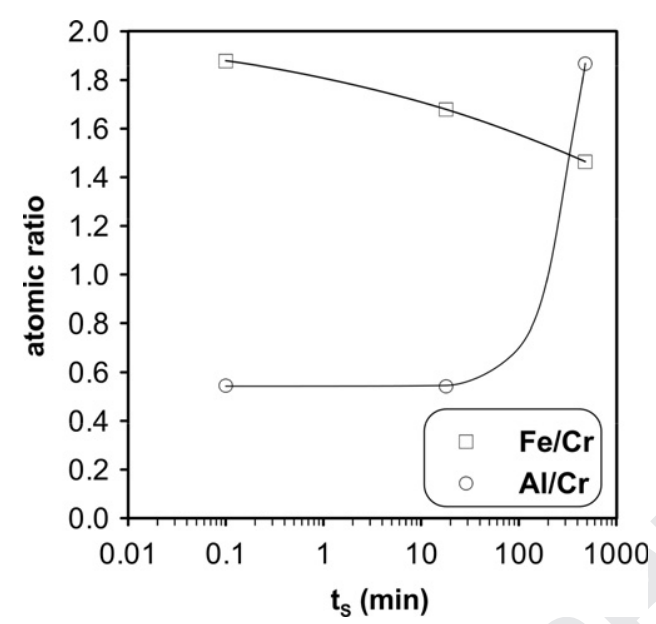

Fig. 10. Comparison of the EDAX signal in pigment particles in the fired porcelanised stoneware specimens at different $t_{\mathrm{S}}$.

Moreover, Al detected by EDX could be assigned to the glassy phase present in the surrounding of the pigment particles, but its increase for the longest soaking time is probably caused by the incorporation of $\mathrm{Al}$ into the structure of the pigment, which is consistent with the evolution of the XRD reflections of the pigment.

The characteristic crystalline phases of the system studied $\left(\mathrm{Fe}_{2} \mathrm{O}_{3}-\mathrm{Cr}_{2} \mathrm{O}_{3}\right.$ solid solution, quartz and mullite) exhibit an approximately logarithmic type of evolution with soaking time at $1180^{\circ} \mathrm{C}$, except for very short times (less than $2 \mathrm{~min}$ ). This departure from the general trend is presumably because glassy phase formation is a gradual process, mainly since a certain time is required to achieve uniform temperature throughout the specimen volume. Initially (at very low $t_{\mathrm{S}}$ values) not enough glassy phase forms to allow complete contact with the crystalline particles present, which is consistent with the microstructure observed in the pieces (Fig. 2). Therefore, the dissolution and crystallization processes do not advance to the extent that would correspond to the operating temperature until a certain time after the furnace has reached $1180{ }^{\circ} \mathrm{C}$. On the other hand, the fact that the evolution of the three crystalline phases displays a similar trend suggests that the same stage controls the rate of quartz dissolution, of mullite crystallization from the glassy phase, and of pigment alteration. Though the identification of this limiting stage is the focus of studies currently in course, the hypothesis may be advanced that this stage is diffusion of the different components through the highly viscous glassy phase located between the different crystalline particles.

The arising changes in the pigment during heat treatment can be interpreted as resulting from the preferential leaching of $\mathrm{Fe}_{2} \mathrm{O}_{3}$ from the pigment structure, owing to the interaction between the pigment and the glassy phase generated by the porcelanised stoneware, since $\mathrm{Fe}_{2} \mathrm{O}_{3}$ is much more soluble in siliceous glasses than $\mathrm{Cr}_{2} \mathrm{O}_{3}$ [15], thus causing the solid solution progressively to approach the $\mathrm{Cr}_{2} \mathrm{O}_{3}$ composition (the $I_{100}$ positions were $33,153^{\circ}$ for hematite and $33,597^{\circ}$ for eskolaite according to the ICDD cards). As a complete solid solution forms in the entire $\mathbf{Q}_{4}$ range of compositions in the $\mathrm{Fe}_{2} \mathrm{O}_{3}-\mathrm{Cr}_{2} \mathrm{O}_{3}$ system, instead of a well-defined crystalline structure which generates XRD reflections in specific angle positions, the increase in $t_{\mathrm{S}}$ produces a distribution of solid solutions of different composition, leading to a quite wide band instead of a clearly defined reflection. The band shift to a higher $2 \theta$ angle than the one corresponding to the $I_{100}$ reflection of pure $\mathrm{Cr}_{2} \mathrm{O}_{3}$ is probably due to the incorporation of some alumina from the glassy phase into the solid solution, since an enrichment in aluminum has been detected in the pigment particles and corundum and $\mathrm{Cr}_{2} \mathrm{O}_{3}$ also form isostructural solid solutions in the whole range of compositions [16]. This would contribute further to the factors that prevent well-defined reflections corresponding to $\mathrm{Cr}_{2} \mathrm{O}_{3}$ from being obtained and, in particular, would cause the reflection to shift beyond the position corresponding to $\mathrm{Cr}_{2} \mathrm{O}_{3}$, since the position of the corundum $I_{100}$ reflection appears at a higher $2 \Theta$ angle $\left(I_{100}\right.$ position at $35,153^{\circ}$, card 00-046-1212, Corundum, syn).

This pigment-porcelanised stoneware interaction mechanism also enables interpreting the notable development of the porosity mentioned in the previous section. The phenomenon can be attributed to the effect of the $\mathrm{Fe}_{2} \mathrm{O}_{3}$ extracted from the pigment. When this oxide dissolves in the glassy phase, in order to maintain the redox equilibrium between $\mathrm{Fe}_{2} \mathrm{O}_{3}$ and $\mathrm{FeO}$, a part of the $\mathrm{Fe}_{2} \mathrm{O}_{3}$ is reduced to $\mathrm{FeO}$, an oxide which acts as a flux in siliceous glasses, lowering the viscosity of the glassy phase and, therefore, favouring pore growth under pressure of the gases present in the pores. In addition, the oxygen released by the reduction would increase the volume of gases captured inside the pores of the porcelanised stoneware, encouraging further the rise in porosity.

\subsection{Evolution of the chromatic coordinates}

The color of the resulting pigmented and non-pigmented porcelanised stoneware specimens varies when $t_{\mathrm{S}}$ is modified, 


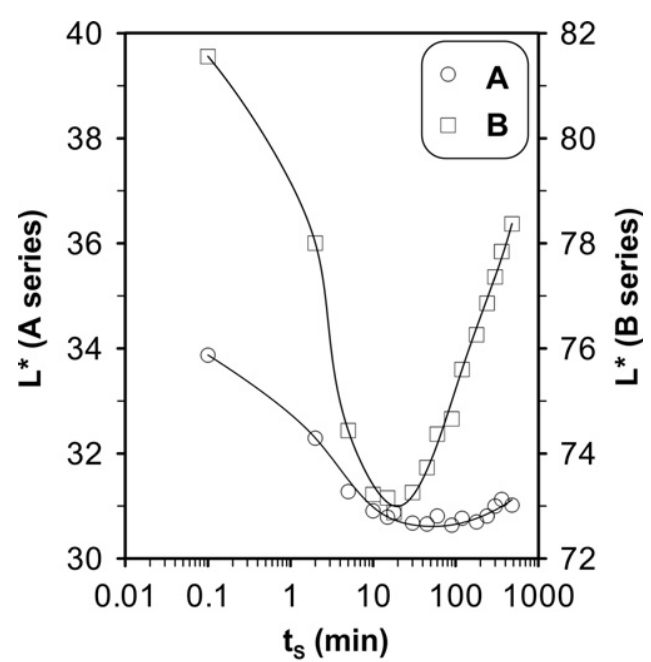

Fig. 11. Evolution of the chromatic coordinate $L^{*}$ versus $t_{\mathrm{S}}$ of the two series of test specimens.

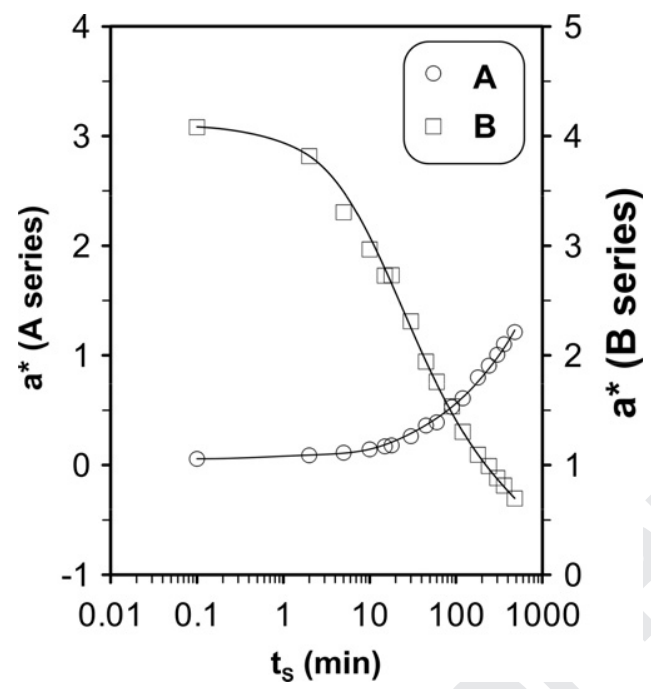

Fig. 12. Evolution of chromatic coordinate $a^{*}$ versus $t_{\mathrm{S}}$ of the two series of test specimens.

as may be observed in the graphs that plot the chromatic coordinates as a function of $t_{\mathrm{S}}$ for the series $\mathrm{A}$ and $\mathrm{B}$ samples (Figs. 11-13). However, the pigment addition alters both the absolute value of the coordinates and their evolution with soaking time. The changes may be attributed to the interactions of light with the different phases present in the samples, i.e. mullite, quartz, glassy phase of variable composition and possibly the pigment, whose coloring characteristics also vary during heat treatment owing to the changes in pigment composition described above.

Porcelanised stoneware lightness $\left(L^{*}\right)$ exhibits a pronounced minimum, presumably related to the maximum development of the glassy phase, since the opacifying effect of the crystalline phases would predominate at either short soaking times or long soaking times (in the former case involving mainly quartz, and in the latter mainly mullite). The incorporation of the pigment shifts the curve towards much lower $L^{*}$ values and smoothes particularly the variations observed, owing to

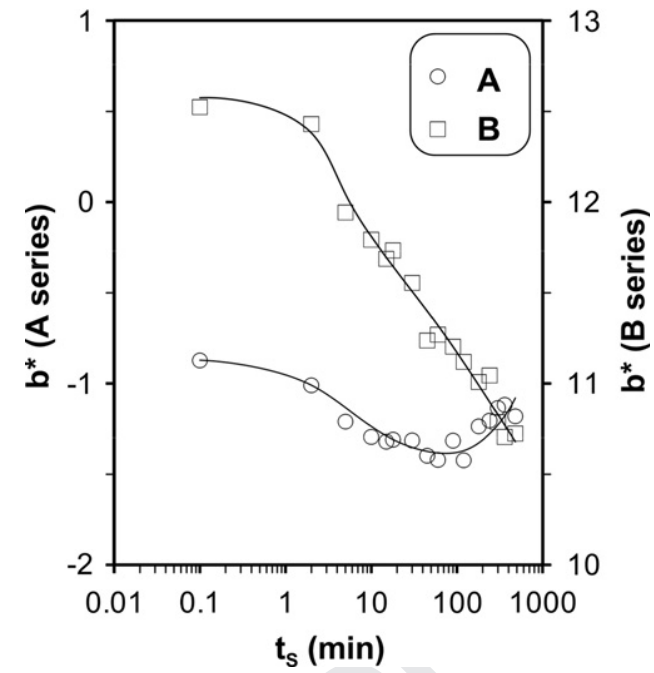

Fig. 13. Evolution of chromatic coordinate $b^{*}$ versus $t_{\mathrm{S}}$ of the two series of test specimens.

the pigment's strong absorption of visible radiation. However, a much more moderate effect of the pigment is observed at lower values of $t_{\mathrm{S}}$, since not enough glassy phase has developed in this case, nor has the glassy phase reached the maximum transparency required for optimum interaction between light and pigment. Despite the changes in pigment composition, the pigment generates a predominant black hue because the $(\mathrm{Fe}, \mathrm{Cr})_{2} \mathrm{O}_{3}$ solid solution has this color in quite a wide range of compositions. As the pigment used in this study contained a larger quantity of $\mathrm{Fe}_{2} \mathrm{O}_{3}$ than $\mathrm{Cr}_{2} \mathrm{O}_{3}$, when $\mathrm{Fe}_{2} \mathrm{O}_{3}$ partly dissolved in the glassy phase, enriching the pigment in $\mathrm{Cr}_{2} \mathrm{O}_{3}$, the predominant black hue would be maintained.

The porcelanised stoneware $a^{*}$ and $b^{*}$ coordinates decrease as $t_{\mathrm{S}}$ increases, attenuating the moderately reddish and clearly yellowish shades obtained at short $t_{\mathrm{S}}$. This may be attributed to the dissolution of coloring impurities (typically $\mathrm{Ti}$ and $\mathrm{Fe}$ compounds from the porcelanised stoneware raw materials) in the glassy phase, in which their effect on color is much more limited. The incorporation of the pigment completely alters these behaviors: the test specimens acquire a slightly bluish hue $\left(b^{*}<0\right)$, which remains practically invariable in the entire range of $t_{\mathrm{S}}$ analyzed, and they acquire a slightly reddish shade which increases when $t_{\mathrm{S}}$ increases. The change in the value of $a^{*}$ can be interpreted as caused by the $\mathrm{Fe}_{2} \mathrm{O}_{3}$ which, extracted from the pigment and incorporated into the glassy phase, tends to develop reddish shades. However, these shades are not intense because the chromium-enriched residual pigment keeps its black color, probably with a green shade, therefore preventing high values of $a^{*}$ from developing, and at the same time preventing variations in $b^{*}$.

\section{Conclusions}

The interaction of the $(\mathrm{Fe}, \mathrm{Cr})_{2} \mathrm{O}_{3}$ black pigment with the glassy phase that forms during porcelanised stoneware firing produces important alterations in the composition of 
1 the pigment and in the porcelanised stoneware microstructure when soaking times are long. At soaking times in the usual range for this type of product, the alterations are not particularly significant, except in color development.

Part of the $\mathrm{Fe}_{2} \mathrm{O}_{3}$ in the pigment is leached, which enriches the pigment in $\mathrm{Cr}_{2} \mathrm{O}_{3}$, and $\mathrm{Al}_{2} \mathrm{O}_{3}$ is probably incorporated into the pigment from the glassy phase. Although the crystal structure of the pigment is not altered, solid solutions are generated in quite a wide range of compositions.

The most significant effect on porcelanised stoneware is a slight increase in mullite formation from the decomposition of the kaolinitic clays and, in particular, a notable increase in pore size at high soaking times, which may be attributed to the increased flowability of the glassy phase and the generation of oxygen from the incorporation of the leached $\mathrm{Fe}_{2} \mathrm{O}_{3}$ into the glassy phase.

\section{References}

[1] K. Shaw, Ceramic Colors and Pottery Decoration, Maclaren, London, 1973.

[2] F. Singer, S.S. Singer, Industrial Ceramics, Chapman and Hall, London, 1962.

[3] R.A. Eppler, Cobalt-free black pigments, American Ceramic Society Bulletin 60 (1981) 562-565.

[4] A. Muan, S. Somiya, Phase relations in the system iron oxide- $-\mathrm{Cr}_{2} \mathrm{O}_{3}$ in air, Journal of the American Ceramic Society 57 (1960) 204-209.

[5] A. Escardino, S. Mestre, A. Barba, V. Beltrán, A. Blasco, Synthesis mechanism of an iron-chromium ceramic pigment, Journal of the American Ceramic Society 83 (2000) 29-32.

[6] A. Escardino, S. Mestre, A. Barba, V. Beltrán, A. Blasco, Kinetic study of black $\mathrm{Fe}_{2} \mathrm{O}_{3}-\mathrm{Cr}_{2} \mathrm{O}_{3}$ pigment synthesis: I, influence of synthesis time and temperature, Journal of the American Ceramic Society 86 (2003) 945-950.

[7] A. Escardino, S. Mestre, A. Barba, C. Feliu, A. Blasco, V. Beltrán, Kinetic study of black $(\mathrm{Fe}, \mathrm{Cr})_{2} \mathrm{O}_{3}$ pigment synthesis reaction: influence of composition and particle size, British Ceramic Transactions 102 (2003) 251-256.

[8] C.J. Byrne, S.G. Kutney, R.A. Pipoly, The effect of glaze composition on the colour and stability of chrome tin pink pigments, Ceramic Engineering and Science Proceedings 15 (1994) 206-223.

[9] A. Escardino, S. Mestre, C. Feliu, P. Jodar, L. Díaz, Stability of $(\mathrm{Cr}) \mathrm{CaO} \cdot \mathrm{SnO}_{2} \cdot \mathrm{SiO}_{2}$ pink pigment in ceramic frits, British Ceramic Transactions 101 (2002) 213-220.

[10] V. Harisanov, R.S. Pavlov, I.T. Marinova, V. Kozhukharov, J.B. Carda, Influence of crystallinity on chromatic parameters of enamels coloured with malayaite pink pigments, Journal of the European Ceramic Society 23 (2003) 429-435.

[11] A.M. Bernardin, Diffusion of $\mathrm{Cr}-\mathrm{Fe}-\mathrm{Al}-\mathrm{Zn}$ pigment in a zirconia glace, Dyes and Pigments 79 (2008) 54-58.

[12] H. Yurdakul, S. Turan, E. Ozel, The mechanism for the colour change of iron chromium black pigments in glazes through transmission electron microscopy techniques, Dyes and Pigments 91 (2011) 126-133.

[13] P.M.T. Cavalcante, M. Dondi, G. Guarini, M. Raimondo, G. Baldi, Colour performance of ceramic nano-pigments, Dyes and Pigments 80 (2009) 226-232.

[14] V. Beltrán, C. Ferrer, V. Bagán, E. Sánchez, J. García, S. Mestre, Influence of pressing powder characteristics and firing temperature on the porous microstructure and stain resistance of porcelain tile, Ceramica Acta 8 (1996) 37-51.

[15] J.R. Taylor, A.C. Bull, Ceramics Glaze Technology, Pergamon Press, Oxford, 1986.

[16] E.M. Levin, C.R. Robbins, H.F. McMurdie, Phase Diagrams for Ceramists, vol. 1, The American Ceramic Society Inc., Columbus (Ohio, USA), 1964. 